\title{
PRÁTICAS APOIADORAS DA REDE SOCIAL DAS PESSOAS COM DEFICIÊNCIA VISUAL: REVISÃO INTEGRATIVA
}

\author{
SOCIAL NETWORK SUPPORT PRACTICES \\ FOR PEOPLE WITH VISUAL IMPAIRMENT: \\ INTEGRATIVE REVIEW
}

\section{PRÁCTICAS DE APOYO DE REDES SOCIALES PARA PERSONAS CON DISCAPACIDAD VISUAL: REVISIÓN INTEGRADORA}

\author{
Jones Sidnei Barbosa de Oliveira ${ }^{1}$ \\ Luciana Pedrosa Leal ${ }^{2}$ \\ Estela Maria Leite Meirelles Monteiro ${ }^{3}$ \\ Cleide Maria Pontes ${ }^{4}$
}

Como citar este artigo: Oliveira JSB, Leal LP, Monteiro EMLM, Pontes CM. Práticas apoiadoras da rede social das pessoas com deficiência visual: revisão integrativa. Rev baiana enferm. 2022;36:e38265.

Objetivo: analisar práticas apoiadoras da rede social no cotidiano de pessoas com deficiência visual. Método: revisão integrativa. As buscas foram realizadas nas bases de dados BDENF, CINAHL, CUIDEN, Medline/PubMed, Scopus, LILACS, Web of Science, bibliotecas virtuais SciELO e Cochrane. Os dados foram coletados em maio de 2018. Resultados: a busca resultou em 2.879 estudos. Foram selecionados 11 artigos, publicados entre 2004 e 2016, com predomínio da família e dos serviços de reabilitação como principais apoiadores. O apoio instrumental foi identificado em nove artigos e as práticas apoiadoras em destaque foram a disponibilidade para a escuta, o diálogo e a companhia social. Conclusão: as práticas apoiadoras ofertadas pela dinâmica da rede social constituem uma estratégia propulsora na qualidade de vida da pessoa com deficiência visual, sendo a família a instituição que mais apoia e está presente em toda a trama de relações e construção social.

Descritores: Pessoas com Deficiência Visual. Transtornos da Visão. Cegueira. Baixa Visão. Apoio Social.

Objective: to analyze practices that support the social network in the daily lives of people with visual impairments. Method: integrative review. The searches were performed in the databases BDENF, CINAHL, CUIDEN, Medline/PubMed, Scopus, LILACS, Web of Science, SciELO and Cochrane virtual libraries. Data were collected in May 2018. Results: the search resulted in 2,879 studies. Ten articles were selected, published between 2004 and 2016, with a predominance of the family and rehabilitation services as main supporters. Instrumental support was identified in nine articles and the prominent supporting practices were the availability for listening, dialogue and social company. Conclusion: the supportive practices offered by the dynamics of the social network constitute a driving strategy in the quality of life of people with visual impairment, and the family is the institution that most supports and is present throughout the web of relationships and social construction.

\footnotetext{
Enfermeiro. Mestre em Enfermagem. Universidade Federal da Bahia. Salvador, Bahia, Brasil. jonessidneyy@gmail.com. https://orcid.org/0000-0002-I I70-2652. Enfermeira. Doutora em Nutrição. Professora na Universidade Federal de Pernambuco. Recife, Pernambuco, Brasil. https://orcid.org/0000-0003-3776-0997.

Enfermeira. Doutora em Enfermagem. Professora na Universidade Federal de Pernambuco. Recife, Pernambuco, Brasil. https://orcid.org/0000-0002-5736-0 I33.

Enfermeira. Doutora em Nutrição. Professora na Universidade Federal de Pernambuco. Recife, Pernambuco, Brasil. https://orcid.org/0000-0003-4707-6873.
} 
Objetivo: analizar las prácticas que apoyan la red social en la vida cotidiana de las personas con discapacidad visual. Método: revisión integradora. Las búsquedas se realizaron en las bases de datos BDENF, CINAHL, CUIDEN, Medlinel PubMed, Scopus, LILACS, Web of Science, SciELO y bibliotecas virtuales Cochrane. Los datos fueron recolectados en mayo de 2018. Resultados: la búsqueda resultó en 2.879 estudios. Se seleccionaron diez artículos, publicados entre 2004 y 2016, con predominio de los servicios de familia y rehabilitación como principales sustentadores. El apoyo instrumental se identificó en nueve artículos y las prácticas de apoyo destacadas fueron la disponibilidad para la escucha, el diálogo y la compañia social. Conclusión: las prácticas de apoyo que ofrece la dinámica de la red social constituyen una estrategia impulsora en la calidad de vida de las personas con discapacidad visual, y la familia es la institución que más apoya y está presente en toda la red de relaciones y construcción social.

Descriptores: Personas con discapacidad visual. Trastornos de la visión. Ceguera. Baja visión. Apoyo social.

\section{Introdução}

A Organização Mundial de Saúde (OMS) estima que 285 milhões de pessoas no mundo tenham deficiência visual. Destas, 39 milhões são cegas e 246 milhões possuem baixa visão ${ }^{(1)}$. No Brasil, dentre as deficiências física, auditiva e intelectual, a deficiência visual é a mais representativa e o Nordeste tem proporção elevada em 3,4\%. Aproximadamente $16 \%$ das pessoas com deficiência visual podem apresentar limitações nos aspectos clínicos, políticos, sociais e/ou dificuldades para realizar atividades habituais, e apenas $4,8 \%$ frequentam serviços de reabilitação ${ }^{(2)}$.

A cegueira pode desencadear inicialmente dificuldade nas relações sociais, romper a inter-relação entre as coisas e o ambiente, possível necessidade de readaptações na comunicação escrita, verbal e corporal. Além disso, alterações na capacidade de autocuidado e dependência provisória de cuidadores provocam a sensação de perda de autonomia da pessoa cega ou com baixa visão. Tais fatores impulsionam o uso com maior precisão de outros sentidos, como o tato e a audição ${ }^{(3-4)}$.

Diante disso, a rede social e suas práticas apoiadoras são essenciais para potencializar o cuidado às pessoas com deficiência visual, amenizar suas angústias/dúvidas e estimular as estratégias de enfrentamento pessoal e coletivo. A rede social se constitui de uma trama de relações que confere a cada sujeito identidade e sentimento de pertença; pode ser de natureza primária (família, amigos, vizinhos, colegas de trabalho) e secundária (instituições formais: saúde, educação, organizações do mercado e terceiro setor) $)^{(5)}$.
As práticas apoiadoras são caraterizadas como apoios fornecidos pelos membros da rede social, ocorre por meio de apoio presencial, emocional, informativo, instrumental e autoapoio, caracterizando-se, portanto, como um conjunto de apoios compartilhados por pessoas em um contexto social $^{(6)}$. A oferta de apoio proporciona aos cegos subsídios para o desenvolvimento de estratégias independentes do cuidado, maior autonomia e ajustamento social $^{(7)}$.

O apoio social de ajuda efetiva e complementar, ofertado principalmente pela rede social primária ou familiar, fortalece laços entre a sociedade e as pessoas com deficiência visual, sobretudo, pelos desafios, lacunas e estigmas sociais enfrentados ${ }^{(8)}$. Logo, justifica-se a necessidade do presente estudo, por identificar e compreender como as práticas apoiadoras contribuem com a autonomia, inclusão, independência e qualidade de vida da pessoa cega e com baixa visão. Diante disso, a presente revisão tem como objetivo analisar práticas apoiadoras da rede social no cotidiano de pessoas com deficiência visual.

\section{Método}

Estudo do tipo revisão integrativa, que possibilita sintetizar achados provenientes de estudos primários e inclusão de experimentos, para uma compreensão completa e rigorosa do fenômeno analisado. Além disso, combina dados da literatura teórica e empírica, análise de problemas metodológicos de um tópico particular, gerando 
um panorama consistente e compreensível de conceitos complexos, teorias e problemas de saúde relevantes ${ }^{(9)}$.

Consoante o rigor metodológico a esse tipo de revisão, percorreram-se seis fases: identificação do tema e seleção da questão da pesquisa; estabelecimento de critérios de inclusão e exclusão de estudos (seleção de amostra); extração de dados dos estudos primários; avaliação crítica dos estudos incluídos; síntese dos resultados e apresentação da revisão ${ }^{(10)}$. A realização desta revisão integrativa também amparou-se no modelo Preferred Reporting Items for Systematic Reviews and Meta-Analyses (PRISMA) ${ }^{(11)}$.

Para construção da pergunta norteadora utilizou-se a estratégia PICO - P: população; I: intervenção; C: comparação; O: outcome (desfecho). Assim, considerou-se: $\mathrm{P}$ - pessoas com deficiência visual; I - rede social; C - sem comparação; O - práticas apoiadoras. Dessa forma, obteve-se a seguinte questão: Quais as práticas apoiadoras da rede social da pessoa com deficiência visual no seu cotidiano?

Para o levantamento dos estudos na literatura estabeleceu-se os seguintes critérios de inclusão: artigos originais, completos e disponíveis na íntegra, que abordassem a temática do estudo, nos idiomas português, inglês e espanhol. Os critérios de exclusão foram trabalhos do tipo teses, dissertações, cartas ao leitor, editoriais, livros ou capítulos de livros, relatos de experiência, revisões sistemáticas, de literatura e integrativa, artigos repetidos nas bases de dados, bem como avaliação de qualidade metodológica e viés (categoria B).

Os dados foram coletados em maio de 2018 nas bases de dados BDENF, Cumulative Index to Nursing and Allied Health Literature (CINAHL), CUIDEN, Medline/PubMed, Scopus, Literatura Latino-Americana e do Caribe em Ciências da Saúde (LILACS), Web of Science, bibliotecas virtuais Scientific Eletronic Library Online (SciELO), Cochrane, com a utilização dos Descritores em Ciências da Saúde (DeCS) e seus respectivos correspondentes em inglês, Medical Subject Headings (MeSH).

Os descritores foram combinados utilizando-se o operador booleano AND. Realizou-se quatro cruzamentos individuais por idioma: 1 - Apoio Social AND Pessoas com Deficiência Visual; Social support AND Visually impaired persons; Apoyo social AND Personas com dãno visual; 2 -Apoio Social AND Transtornos da Visão; Social support AND Vision disorders; Apoyo social AND Trastornos de la visión; 3 - Apoio Social AND Cegueira; Social support AND Blindness; Apoyo social AND Cegera; 4 - Apoio Social AND Baixa Visão; Social support AND Low vision; Apoyo social AND Baja visión. Obteve-se um total de 2.879 publicações (Tabela 1).

Tabela 1 - Quantitativo de publicações encontradas nos cruzamentos dos descritores nas bases de dados e bibliotecas de saúde. Recife, Pernambuco, Brasil - 2018. N=2.879

\begin{tabular}{l|c|c|c|c}
\hline \multirow{2}{*}{ Base de dados } & \multicolumn{4}{c}{ Cruzamentos } \\
\cline { 2 - 5 } & $\mathbf{1}$ & $\mathbf{2}$ & $\mathbf{3}$ & $\mathbf{4}$ \\
\hline CINAHL & 1 & 30 & 20 & 20 \\
Scopus & 52 & 70 & 119 & 70 \\
LILACS & 9 & 8 & 6 & 10 \\
Web of Science & 30 & 72 & 169 & 270 \\
Medline/PubMed & 155 & 881 & 453 & 391 \\
BDENF & - & - & - & - \\
CUIDEN & - & - & - & - \\
SciELO & 2 & 7 & 10 & 10 \\
Cochrane & 3 & 6 & 1 & 4 \\
Total & 252 & 1.074 & 778 & 775 \\
\hline
\end{tabular}

Fonte: Elaboração própria.

Nota: Sinal convencional utilizado:

- Dado numérico igual a zero não resultante de arredondamento. 
Do total de publicações encontradas (2.879) foram excluídas 92, por não corresponderem ao idioma pesquisado. Descartou-se 344 por não disponibilidade, textos incompletos e/ou indisponíveis no Sistema de Comutação Bibliográfica (COMUT). Após a leitura de 2.443 títulos, eliminou-se 1.761 por não se adequarem à temática do estudo, 156 trabalhos do tipo revisão, 32 relatos de experiência e 109 duplicados nas mesmas bases de dados. Em seguida, procedeu-se a leitura de 384 resumos das publicações restantes, das quais foram eliminados 22 editoriais, 10 teses, 9 dissertações, 7 trabalhos do tipo carta, 12 notas, 2 pesquisas curtas e 3 do tipo conferências. Ainda nessa fase, eliminou-se 272 publicações por não responderem à pergunta condutora.
Para leitura na íntegra foram selecionados 47 artigos, dos quais, 35 não respondiam à pergunta de pesquisa, restando 12 artigos elegíveis. Para avaliar o rigor metodológico, os 12 artigos foram analisados com base no instrumento Critical Appraisal Skills Programm (CASP), que classifica os estudos em boa qualidade metodológica e viés reduzido (categoria A, 6 a 10 pontos); e qualidade metodológica satisfatória (categoria B, no mínimo 5 pontos). Considerou-se apenas os artigos classificados na categoria $\mathrm{A}^{(12)}$. Dessa maneira, 1 artigo foi excluído por se enquadrar na categoria $\mathrm{B}$, o que totalizou 11 artigos finais para discussão (Fluxograma 1). 
Fluxograma 1 - Resultados da seleção dos artigos para revisão integrativa

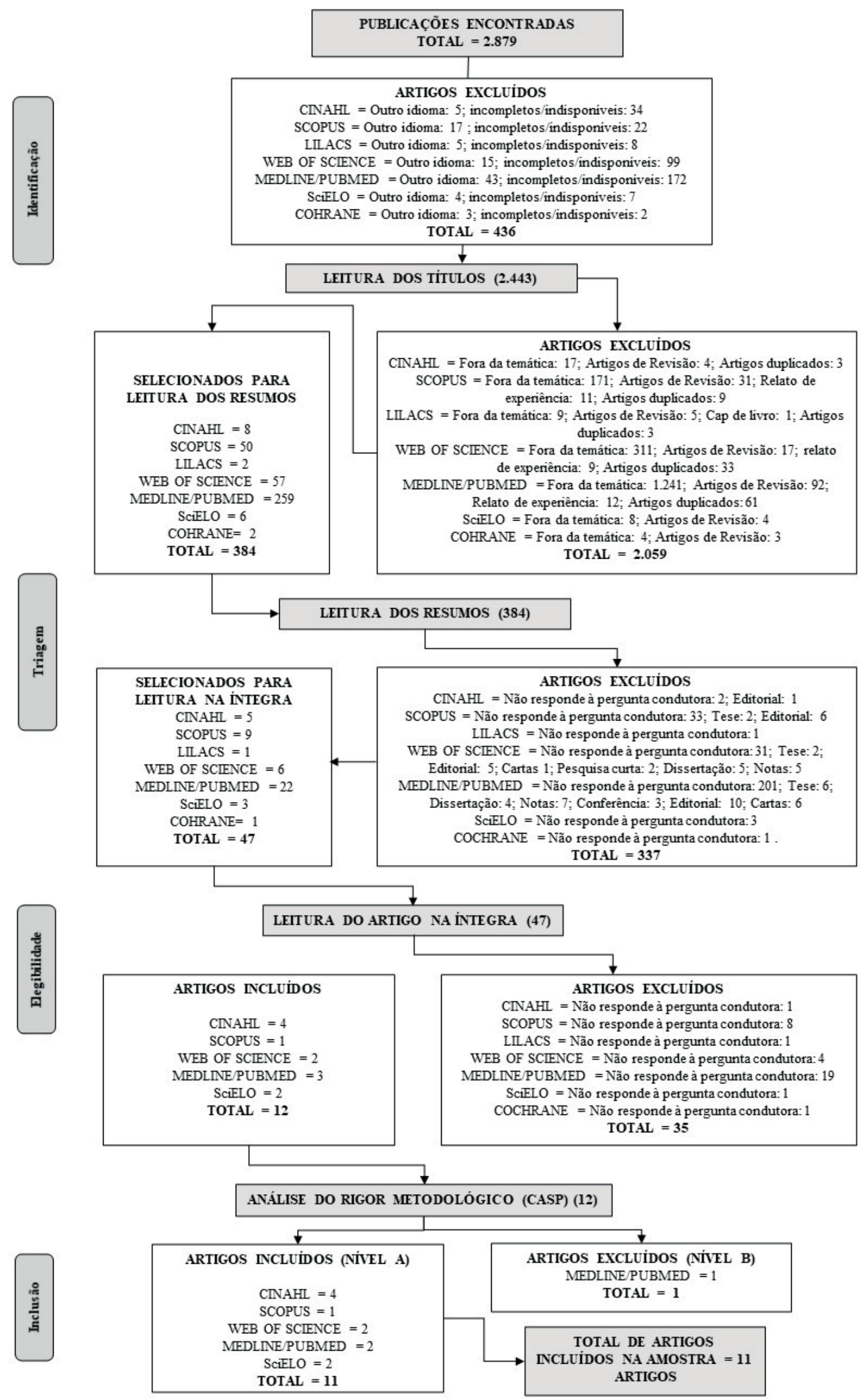

Fonte: Elaboração própria. 
O nível de evidência foi identificado e classificado nos níveis: 1 - evidências resultantes de revisão sistemática ou meta-análise de ensaios clínicos randomizados; 2 - evidências de ensaios clínicos randomizados bem desenhados; 3 - ensaios clínicos sem randomização; 4 - estudos de casos-controles e coortes; 5 - revisões sistemáticas de estudos descritivos e qualitativos; 6 - estudos descritivos ou qualitativos individuais; 7 - opiniões de comitês de especialistas, autoridades e/ou relatórios de comissões de peritos ${ }^{(13)}$.

Os resultados foram dispostos em quadro contendo variáveis relacionadas à identificação dos artigos: autores e ano de publicação, base de dados, objetivos, amostra, nível de evidência, práticas apoiadoras, tipo de apoio, quem apoia e situação do cotidiano. A extração dessas informações deu-se mediante instrumento validado e adaptado $^{(14)}$. Realizou-se a análise crítica dos trabalhos selecionados à luz da Rede Social ${ }^{(5)}$, com ênfase nas pessoas com deficiência visual, comparando-se os conhecimentos teóricos às implicações resultante da presente revisão.

\section{Resultados}

Dos 11 artigos finais selecionados, 4 foram extraídos da CINAHL ${ }^{(15-18)}, 2$ da PubMed ${ }^{(19-20)}$, 2 da SciElO ${ }^{(21-22)}, 1$ da Scopus ${ }^{(23)}$ e 2 da Web of Science ${ }^{(24-25)}$. Não foram encontradas publicações nas bases BDENF e CUIDEN.

Quanto ao tipo de delineamento dos estudos avaliados, evidenciou-se, na amostra, o predomínio de artigos descritivos qualitativos e quantitativos: quatro estudos descritivos qualita$\operatorname{tivos}^{(17-18,21-22)}$, três quantitativos não-experimentais $^{(15,24-25)}$, dois casos-controles ${ }^{(20,23)}$, um de tipo coorte $^{(19)}$, e um quase-experimental ${ }^{(16)}$, com predominância do nível de evidência seis ${ }^{(15-18,21-22,24-25)}$, seguido do nível de evidência quatro ${ }^{(16,19-20,23)}$.

Quanto ao idioma, verificou-se que a língua inglesa foi a mais frequente (nove artigos) seguida da língua portuguesa (dois artigos). Os artigos encontrados compreendem os anos de publicação de 2004 a 2016, em periódicos dos Estados Unidos ${ }^{(16-19,24)}$, Reino Unido ${ }^{(15,20,23,25)} \mathrm{e}$
Brasil $^{(21-22)}$. Entre eles, três foram publicados na área médica ${ }^{(19,25)}$, um em revistas de enfermagem ${ }^{(22)}$ e psicologia ${ }^{(15)}$, outro na área de saúde pública ${ }^{(23)}$, de saúde coletiva ${ }^{(21)}$ e cinco artigos publicados em revistas sem especificação de área ${ }^{(16-18,20,24)}$.

A temática da rede social enfatizou as pessoas com deficiência visual em situações diversas do cotidiano e em diferentes fases da vida, como a da criança ${ }^{(21,25)}$, da adolescência ${ }^{(20-21,23)}$, da fase $\operatorname{adulta}^{(16-18,22,24-25)}$ e da velhice ${ }^{(15,19,24)}$.

As práticas apoiadoras em maior evidência foram aquelas direcionadas à disponibilidade para a escuta, o diálogo e a companhia social $^{(16-17,19-21,24-25)}, \operatorname{logo}$ em seguida, a ajuda prática, como limpeza da casa, realização de compras, auxílio com transporte e assistência doméstica no $\operatorname{geral}^{(15,19,21)}$. Apoios do tipo valorização da competência, da independência, aprovação de atitudes e elevação da autoestima do cego ou com baixa visão foram pouco abordados nos artigos ${ }^{(18,24)}$.

O apoio instrumental foi identificado em nove $\operatorname{artigos}^{(15-17,19-23,25)}$, o apoio emocional $^{(16-18,20-21,23-25)}$ e informativo ${ }^{(15-17,21-25)}$ em oito, e apenas três trouxeram a discussão sobre o autoapoio $^{(18,22,24)}$ e o apoio presencial ${ }^{(18-20)}$. No que se refere à rede social primária, a família ocupa posição de destaque como grupo social apoiador $^{(15-16,18-23,25)}$. A rede social secundária, representada pelas instituições governamentais, filantrópicas, gestores e profissionais de saúde, foi evidenciada em sete artigos ${ }^{(15-16,19,21-22,24-25)}$. O enfermeiro, dentro da rede social secundária, foi citado em duas publicações ${ }^{(19,25)}$ e o terapeuta em reabilitação em três ${ }^{(15,16,24)}$.

Em relação à rotina diária, a situação do cotidiano reflete principalmente a dificuldade para a realização de tarefas diárias ${ }^{(15,19,22,24)}$ e adaptação à nova realidade imposta pela deficiência visual $^{(16-18,20-21,23-25)}$. Três artigos focaram a pessoa com deficiência visual enquanto ser holístico, que possui necessidades para além da reabilitação clínica, na condição de estudante ${ }^{(20,23)}$ e pais cegos que cuidam de seus filhos ${ }^{(22)}$.

Os atores sociais presentes no cenário escolar foram representados principalmente por professores ${ }^{(16,23,25)}$, seguido dos colegas de sala de 
aula $^{(20,23)}$. No que se refere às relações estabelecidas no ambiente de trabalho, um artigo ${ }^{(17)}$ mencionou os colegas, supervisores e empregadores como potenciais apoiadores. Os estudos foram selecionados conforme autores, ano de publicação, base de dados, objetivos, amostra, nível de evidência, situação do cotidiano, práticas apoiadoras, tipo de apoio e apoiador (Quadro 1).

Quadro 1 - Síntese das características dos artigos selecionados para o estudo

(continua)

\begin{tabular}{|c|c|c|c|c|c|}
\hline $\begin{array}{l}\text { Autor/Ano/ Base de } \\
\text { dados }\end{array}$ & Objetivos & $\begin{array}{l}\text { Amostra/ } \\
\text { Nivel de } \\
\text { evidência }\end{array}$ & $\begin{array}{l}\text { Situação do } \\
\text { cotidiano }\end{array}$ & $\begin{array}{c}\text { Práticas } \\
\text { apoiadoras }\end{array}$ & $\begin{array}{l}\text { Tipo de } \\
\text { apoio }\end{array}$ \\
\hline $\begin{array}{l}\text { Cimarolli VR, } \\
\text { Boerner K, } \\
\text { Reinhardt JP, } \\
\text { Horowitz A }{ }^{(15)} \text {; } \\
2013 \text {. } \\
\text { CINAHL }\end{array}$ & $\begin{array}{l}\text { Investigar } \\
\text { alterações na } \\
\text { superproteção } \\
\text { percebida } \\
\text { ao longo do } \\
\text { tempo, em } \\
\text { relação ao } \\
\text { recebimento } \\
\text { de apoio } \\
\text { instrumental } \\
\text { e uso de } \\
\text { serviço de } \\
\text { reabilitação } \\
\text { da visão. }\end{array}$ & $\begin{array}{l}584 \text { idosos } \\
\text { com } \\
\text { deficiência } \\
\text { visual. } \\
\text { Nivel de } \\
\text { evidência } 4\end{array}$ & $\begin{array}{l}\text { Medo de cair, } \\
\text { viver sozinhas, } \\
\text { incapacidade } \\
\text { funcional e } \\
\text { dificuldade } \\
\text { para realizar } \\
\text { tarefas diárias. }\end{array}$ & $\begin{array}{l}\text { Ajuda com } \\
\text { compras, } \\
\text { limpeza, correio } \\
\text { e finanças. } \\
\text { Ensino, } \\
\text { reabilitação, } \\
\text { orientação } \\
\text { e auxílio na } \\
\text { mobilidade. }\end{array}$ & $\begin{array}{l}\text { Instrumental } \\
\text { Informativo }\end{array}$ \\
\hline $\begin{array}{l}\text { Guerette AR, } \\
\text { Smedema SM }{ }^{(16)} \text {; } \\
2011 . \\
\text { CINAHL }\end{array}$ & $\begin{array}{l}\text { Investigar } \\
\text { a relação } \\
\text { entre o } \\
\text { apoio social } \\
\text { percebido e } \\
\text { bem-estar em } \\
\text { uma amostra } \\
\text { nacional de } \\
\text { pessoas com } \\
\text { deficiências } \\
\text { visuais } \\
\text { usando } \\
\text { análise de } \\
\text { regressão. }\end{array}$ & $\begin{array}{l}199 \text { pessoas } \\
\text { com } \\
\text { deficiência } \\
\text { visual. } \\
\text { Nível de } \\
\text { evidência } 3\end{array}$ & $\begin{array}{l}\text { Adaptação } \\
\text { à perda } \\
\text { da visão, } \\
\text { insatisfação } \\
\text { com a vida, } \\
\text { sensação } \\
\text { de mal-estar } \\
\text { e sintomas } \\
\text { depressivos, } \\
\text { interações } \\
\text { sociais e } \\
\text { resolução de } \\
\text { conflitos. }\end{array}$ & $\begin{array}{l}\text { Oferta de } \\
\text { emprego, } \\
\text { interação, } \\
\text { diálogo } \\
\text { e escuta, } \\
\text { educação em } \\
\text { sala de aula, } \\
\text { suporte no uso } \\
\text { de habilidades } \\
\text { interpessoais } \\
\text { (fazer e manter } \\
\text { amigos e } \\
\text { parceiros } \\
\text { românticos). }\end{array}$ & $\begin{array}{l}\text { Emocional } \\
\text { Instrumental } \\
\text { Informativo }\end{array}$ \\
\hline $\begin{array}{l}\text { Papakonstantinou D, } \\
\text { Papadopoulos } \mathrm{K}^{(17)} \text {; } \\
2009 . \\
\text { CINAHL }\end{array}$ & $\begin{array}{l}\text { Investigar o } \\
\text { apoio social } \\
\text { no local de } \\
\text { trabalho para } \\
\text { pessoas com } \\
\text { deficiência } \\
\text { visual. }\end{array}$ & $\begin{array}{l}15 \text { pessoas } \\
\text { com } \\
\text { deficiência } \\
\text { visual. } \\
\text { Nível de } \\
\text { evidência } 4\end{array}$ & $\begin{array}{l}\text { Adaptação } \\
\text { ao ambiente } \\
\text { de trabalho } \\
\text { público e } \\
\text { privado. }\end{array}$ & $\begin{array}{l}\text { Companhia na } \\
\text { viagem (guia ou } \\
\text { acompanhante) } \\
\text { simulação } \\
\text { prática, } \\
\text { flexibilidade e } \\
\text { compreensão } \\
\text { de atrasos ou } \\
\text { faltas, igual } \\
\text { tratamento, } \\
\text { reconhecimento } \\
\text { e confiança, } \\
\text { convites para } \\
\text { atividades } \\
\text { e excursões } \\
\text { externas. }\end{array}$ & $\begin{array}{l}\text { Emocional } \\
\text { Instrumental } \\
\text { Informativo }\end{array}$ \\
\hline
\end{tabular}


Quadro 1 - Síntese das características dos artigos selecionados para o estudo (continuação)

\begin{tabular}{|c|c|c|c|c|c|}
\hline $\begin{array}{l}\text { Autor/Ano/ Base de } \\
\text { dados }\end{array}$ & Objetivos & $\begin{array}{l}\text { Amostra/ } \\
\text { Nivel de } \\
\text { evidência }\end{array}$ & $\begin{array}{l}\text { Situação do } \\
\text { cotidiano }\end{array}$ & $\begin{array}{c}\text { Práticas } \\
\text { apoiadoras }\end{array}$ & $\begin{array}{l}\text { Tipo de } \\
\text { apoio }\end{array}$ \\
\hline $\begin{array}{l}\text { Singletary C, } \\
\text { Goodwyn MA, } \\
\text { Carter AP }{ }^{(18)} \text {; } \\
2009 . \\
\text { CINAHL }\end{array}$ & $\begin{array}{l}\text { Examinar } \\
\text { as relações } \\
\text { entre redes } \\
\text { de apoio } \\
\text { social dos } \\
\text { indivíduos } \\
\text { legalmente } \\
\text { cegos e os } \\
\text { níveis de } \\
\text { esperança } \\
\text { relatados em } \\
\text { um centro de } \\
\text { treinamento } \\
\text { para pessoas } \\
\text { cegas. }\end{array}$ & $\begin{array}{l}24 \text { estudantes } \\
\text { com } \\
\text { deficiência } \\
\text { visual. } \\
\text { Nível de } \\
\text { evidência } 4\end{array}$ & $\begin{array}{l}\text { Treinamento } \\
\text { e reabilitação } \\
\text { para } \\
\text { alcançar vida } \\
\text { independente } \\
\text { e produtiva, } \\
\text { esperança de } \\
\text { vida. }\end{array}$ & $\begin{array}{l}\text { Valorização da } \\
\text { competência e } \\
\text { independência, } \\
\text { ensino de } \\
\text { habilidades } \\
\text { gerais. }\end{array}$ & $\begin{array}{l}\text { Autoapoio } \\
\text { Emocional } \\
\text { Presencial }\end{array}$ \\
\hline $\begin{array}{l}\text { Hong T, Mitchell P, } \\
\text { Burlutsky G, } \\
\text { Fong CSU, } \\
\text { Rochtchina E, } \\
\text { Wang JJ }^{(19)} \text {; } \\
2013 . \\
\text { PubMed }\end{array}$ & $\begin{array}{l}\text { Avaliar o } \\
\text { impacto da } \\
\text { deficiência } \\
\text { visual e } \\
\text { cegueira } \\
\text { sobre } \\
\text { o uso } \\
\text { incidente } \\
\text { de serviços } \\
\text { de apoio da } \\
\text { comunidade } \\
\text { no Blue } \\
\text { Mountains } \\
\text { Eye Study. }\end{array}$ & $\begin{array}{l}3.654 \\
\text { pessoas com } \\
\text { deficiência } \\
\text { visual. } \\
\text { Nível de } \\
\text { evidência } 3\end{array}$ & $\begin{array}{l}\text { Pessoas } \\
\text { idosas com } \\
\text { deficiência } \\
\text { visual que são } \\
\text { domiciliados } \\
\text { e necessitam } \\
\text { de cuidados } \\
\text { em longo } \\
\text { prazo, } \\
\text { morando } \\
\text { sozinhos ou } \\
\text { não. }\end{array}$ & $\begin{array}{l}\text { Cuidados } \\
\text { pessoais, } \\
\text { assistência } \\
\text { doméstica, } \\
\text { cuidados de } \\
\text { enfermagem, } \\
\text { entrega de } \\
\text { refeições, } \\
\text { transporte, } \\
\text { limpeza da casa, } \\
\text { fazer compras } \\
\text { e visitas } \\
\text { domiciliares. }\end{array}$ & $\begin{array}{l}\text { Presencial } \\
\text { Instrumental }\end{array}$ \\
\hline $\begin{array}{l}\text { Kef S, Deković } \mathrm{M}^{(20)} \text {; } \\
2004 . \\
\text { PubMed }\end{array}$ & $\begin{array}{l}\text { Comparar a } \\
\text { percepção } \\
\text { do nível de } \\
\text { apoio social } \\
\text { e bem-estar } \\
\text { dos } \\
\text { adolescentes } \\
\text { com } \\
\text { deficiência } \\
\text { visual e } \\
\text { adolescentes } \\
\text { sem } \\
\text { deficiência. }\end{array}$ & $\begin{array}{l}178 \\
\text { adolescentes } \\
\text { com } \\
\text { deficiência } \\
\text { visual e } 338 \\
\text { adolescentes } \\
\text { videntes. } \\
\text { Nível de } \\
\text { evidência } 3\end{array}$ & $\begin{array}{l}\text { Adolescentes } \\
\text { escolares com } \\
\text { deficiência } \\
\text { visual que } \\
\text { precisam de } \\
\text { atendimento } \\
\text { em } \\
\text { institutos de } \\
\text { reabilitação, } \\
\text { sua } \\
\text { percepção } \\
\text { de apoio } \\
\text { percebido } \\
\text { e recebido, } \\
\text { influenciando } \\
\text { no seu } \\
\text { bem-estar } \\
\text { psicológico. }\end{array}$ & $\begin{array}{l}\text { Oferta de } \\
\text { companhia } \\
\text { diária, escuta } \\
\text { e diálogo, } \\
\text { realização de } \\
\text { atividades } \\
\text { escolares, o } \\
\text { ato de brincar } \\
\text { (lazer). }\end{array}$ & $\begin{array}{l}\text { Emocional } \\
\text { Instrumental } \\
\text { Presencial }\end{array}$ \\
\hline
\end{tabular}


Quadro 1 - Síntese das características dos artigos selecionados para o estudo

(continuação)

\begin{tabular}{|c|c|c|c|c|c|}
\hline $\begin{array}{l}\text { Autor/Ano/ Base de } \\
\text { dados }\end{array}$ & Objetivos & $\begin{array}{l}\text { Amostra/ } \\
\text { Nivel de } \\
\text { evidência }\end{array}$ & $\begin{array}{l}\text { Situação do } \\
\text { cotidiano }\end{array}$ & $\begin{array}{c}\text { Práticas } \\
\text { apoiadoras }\end{array}$ & $\begin{array}{l}\text { Tipo de } \\
\text { apoio }\end{array}$ \\
\hline $\begin{array}{l}\text { Barbieri MC, } \\
\text { Broekman GVDZ, } \\
\text { Souza ROD, } \\
\text { Lima RAG, Wernet M, } \\
\text { Dupas G } \\
2016 . \\
\text { SciELO }\end{array}$ & $\begin{array}{l}\text { Conhecer as } \\
\text { interações } \\
\text { estabelecidas } \\
\text { entre a rede } \\
\text { de apoio } \\
\text { social e as } \\
\text { famílias de } \\
\text { crianças e } \\
\text { adolescentes } \\
\text { com } \\
\text { deficiência } \\
\text { visual. }\end{array}$ & $\begin{array}{l}18 \text { famílias } \\
\text { de crianças e } \\
\text { adolescentes } \\
\text { com } \\
\text { deficiência } \\
\text { visual. } \\
\text { Nível de } \\
\text { evidência } 4\end{array}$ & $\begin{array}{l}\text { Famílias que } \\
\text { possuem } \\
\text { crianças e } \\
\text { adolescentes } \\
\text { com } \\
\text { deficiência } \\
\text { visual, } \\
\text { vivenciando } \\
\text { momentos de } \\
\text { dificuldade } \\
\text { para acesso } \\
\text { aos serviços } \\
\text { de apoio ao } \\
\text { paciente cego } \\
\text { ou com baixa } \\
\text { visão. }\end{array}$ & $\begin{array}{l}\text { Acompanhar em } \\
\text { consulta médica, } \\
\text { conversar } \\
\text { e escutar } \\
\text { (diálogo), } \\
\text { levar ao teatro, } \\
\text { fazer ligações } \\
\text { telefônicas, } \\
\text { oferta de } \\
\text { exames, ensinar } \\
\text { técnicas para } \\
\text { atividades } \\
\text { diárias (vestir, } \\
\text { alimentar e dar } \\
\text { banho), oferta } \\
\text { de material } \\
\text { educativo, } \\
\text { auxílio com } \\
\text { transporte } \\
\text { e oferta de } \\
\text { óculos. }\end{array}$ & $\begin{array}{l}\text { Emocional } \\
\text { Instrumental } \\
\text { Informativo }\end{array}$ \\
\hline $\begin{array}{l}\text { Pagliuca LMF, } \\
\text { Uchoa RS, } \\
\text { Machado MMT }{ }^{(22)} \text {; } \\
2009 . \\
\text { SciELO }\end{array}$ & $\begin{array}{l}\text { Refletir sobre } \\
\text { dificuldades } \\
\text { e estratégias } \\
\text { de pais cegos } \\
\text { quando } \\
\text { cuidam } \\
\text { de seus } \\
\text { filhos e a } \\
\text { contribuição } \\
\text { da rede } \\
\text { social } \\
\text { para sua } \\
\text { autonomia. } \\
\end{array}$ & $\begin{array}{l}\text { Duas } \\
\text { famílias: uma } \\
\text { com pai } \\
\text { cego, outra } \\
\text { com mãe } \\
\text { cega. } \\
\text { Nível de } \\
\text { evidência } 4\end{array}$ & $\begin{array}{l}\text { Dificuldades, } \\
\text { estratégias e } \\
\text { manutenção } \\
\text { da autonomia } \\
\text { de pais cegos } \\
\text { que cuidam } \\
\text { de seus filhos. }\end{array}$ & $\begin{array}{l}\text { Ensinar a dar } \\
\text { banho no } \\
\text { filho, trocar e } \\
\text { vesti-lo, cuidar } \\
\text { do umbigo, } \\
\text { instruções } \\
\text { de como } \\
\text { identificar febre } \\
\text { e secreções no } \\
\text { ferimento das } \\
\text { crianças. }\end{array}$ & $\begin{array}{l}\text { Informativo } \\
\text { Instrumental } \\
\text { Autoapoio }\end{array}$ \\
\hline $\begin{array}{l}\text { Pinquart M, } \\
\text { Pfeiffer JP }{ }^{(23)} \text {; } \\
2013 \text {. } \\
\text { Scopus }\end{array}$ & \begin{tabular}{|l|} 
Avaliar a \\
percepção da \\
disponibilidade \\
de apoio dos \\
pais, colegas e \\
professores em \\
adolescentes \\
com e sem \\
deficiência \\
visual.
\end{tabular} & $\begin{array}{l}104 \\
\text { estudantes } \\
\text { com } \\
\text { deficiência } \\
\text { visual e } 232 \\
\text { videntes. } \\
\text { Nível de } \\
\text { evidência } 3\end{array}$ & $\begin{array}{l}\text { Estudantes } \\
\text { de escolas } \\
\text { residenciais } \\
\text { (específicas } \\
\text { para cegos), } \\
\text { longe de casa } \\
\text { e da familia, } \\
\text { "vivendo" em } \\
\text { dormitórios } \\
\text { compartilhados. }\end{array}$ & $\begin{array}{l}\text { Oferta de } \\
\text { atividades } \\
\text { extracurriculares, } \\
\text { auxílio no } \\
\text { manuseio } \\
\text { de objetos } \\
\text { escolares, relação } \\
\text { de confiança, } \\
\text { encorajamento } \\
\text { para realizar } \\
\text { tarefas e } \\
\text { disponibilidade } \\
\text { para oferta de } \\
\text { aconselhamentos. }\end{array}$ & $\begin{array}{l}\text { Emocional } \\
\text { Instrumental } \\
\text { Informativo }\end{array}$ \\
\hline
\end{tabular}


Quadro 1 - Síntese das características dos artigos selecionados para o estudo (conclusão)

\begin{tabular}{|c|c|c|c|c|c|}
\hline $\begin{array}{l}\text { Autor/Ano/ Base de } \\
\text { dados }\end{array}$ & Objetivos & $\begin{array}{l}\text { Amostra/ } \\
\text { Nivel de } \\
\text { evidência }\end{array}$ & $\begin{array}{l}\text { Situação do } \\
\text { cotidiano }\end{array}$ & $\begin{array}{c}\text { Práticas } \\
\text { apoiadoras }\end{array}$ & $\begin{array}{l}\text { Tipo de } \\
\text { apoio }\end{array}$ \\
\hline $\begin{array}{l}\text { Kempen GIJM, } \\
\text { Ballemans J, } \\
\text { Ranchor AV, } \\
\text { Van Rens GHMB, } \\
\text { Zijlstra GAR }{ }^{(24)} \text {; } \\
2012 . \\
\text { Web of Science }\end{array}$ & $\begin{array}{l}\text { Examinar o } \\
\text { impacto da } \\
\text { baixa } \\
\text { visão na } \\
\text { saúde em } \\
\text { relação à } \\
\text { qualidade } \\
\text { de vida, } \\
\text { incluindo } \\
\text { sentimentos } \\
\text { de ansiedade } \\
\text { e apoio } \\
\text { social entre } \\
\text { adultos mais } \\
\text { velhos que } \\
\text { procuram os } \\
\text { serviços de } \\
\text { reabilitação } \\
\text { da visão. }\end{array}$ & $\begin{array}{l}149 \text { adultos } \\
\text { com } \\
\text { deficiência } \\
\text { visual. } \\
\text { Nível de } \\
\text { evidência } 4\end{array}$ & $\begin{array}{l}\text { Adultos mais } \\
\text { velhos com } \\
\text { baixa visão } \\
\text { atendidos em } \\
\text { serviços de } \\
\text { reabilitação, } \\
\text { com } \\
\text { relatos de } \\
\text { dificuldades } \\
\text { em atividades } \\
\text { de vida diária, } \\
\text { depressão e } \\
\text { sentimentos } \\
\text { de ansiedade. }\end{array}$ & $\begin{array}{l}\text { Companhia } \\
\text { social e apoio } \\
\text { emocional } \\
\text { diariamente, } \\
\text { elevar a } \\
\text { autoestima } \\
\text { e aprovar } \\
\text { as atitudes/ } \\
\text { iniciativas. }\end{array}$ & $\begin{array}{l}\text { Emocional } \\
\text { Autoapoio } \\
\text { Informativo }\end{array}$ \\
\hline $\begin{array}{l}\text { Boyce T, } \\
\text { Dahlmann-Noor A, } \\
\text { Bowman R, Keil S }{ }^{(25)} \text {; } \\
2015 \text {. } \\
\text { Web of Science }\end{array}$ & $\begin{array}{l}\text { Analisar } \\
\text { questões } \\
\text { relacionadas } \\
\text { com o } \\
\text { processo de } \\
\text { certificação e } \\
\text { de registro } \\
\text { de crianças e } \\
\text { jovens com } \\
\text { perda de } \\
\text { visão. }\end{array}$ & $\begin{array}{l}52 \text { assistentes } \\
\text { sociais e } \\
\text { professores, } \\
26 \text { pais de } \\
\text { bebês e } \\
\text { crianças com } \\
\text { deficiência } \\
\text { visual. } \\
\text { Nível de } \\
\text { evidência } 4\end{array}$ & $\begin{array}{l}\text { Pais de } \\
\text { crianças e } \\
\text { jovens com } \\
\text { deficiência } \\
\text { visual no } \\
\text { enfrentamento } \\
\text { ao processo } \\
\text { burocrático } \\
\text { para conseguir } \\
\text { o certificado } \\
\text { e registro da } \\
\text { doença. }\end{array}$ & $\begin{array}{l}\text { Oferta do } \\
\text { Certificado e } \\
\text { Registro da } \\
\text { Deficiência } \\
\text { Visual, auxílio } \\
\text { da aceitação do } \\
\text { bebê cego ou } \\
\text { com baixa visão, } \\
\text { encaminhamento } \\
\text { para serviços } \\
\text { de referências, } \\
\text { oferta de escolas } \\
\text { especializadas. }\end{array}$ & $\begin{array}{l}\text { Instrumental } \\
\text { Informativo } \\
\text { Emocional }\end{array}$ \\
\hline
\end{tabular}

Fonte: Elaboração própria.

\section{Discussão}

Os artigos selecionados revelam que a temática da rede social para pessoas com deficiência visual necessita ser mais pesquisada no Brasil. Tal condição vai de encontro à visibilidade que deveria ser direcionada a esse público, principalmente à sua rede social, pois esse país possui alta proporção de pessoas com deficiência visual, com mais de 6,5 milhões de pessoas com algum tipo de deficiência visual, dos quais 528.624 são cegos e 6.056.654 possuem baixa visão ou visão subnormal - grande e permanente dificuldade de enxergar ${ }^{(26)}$.

Para alcançar a inclusão social dessa população é necessária uma rede social atuante, que se faça presente no dia a dia e proporcione, na trama das relações existentes, o suporte necessário ao pleno desenvolvimento da cidadania das pessoas cegas ou com baixa visão ${ }^{(18)}$. As práticas apoiadoras são caracterizadas como oferta de informações, auxílio material, benefícios sociais e também apoio emocional $^{(21)}$. O conjunto desses apoios são compartilhados coletivamente por grupos e pessoas, o que se denomina rede social ${ }^{(5-6)}$.

O conceito de rede social está cunhado no estabelecimento de relações criadas em pontos que se interligam e se cruzam por conexões e cadeias, pode abarcar três ou mais pessoas no intuito de construir relações interpessoais, originando um emaranhado, que pode ser de maior ou menor densidade. Rede social envolve trama 
de relações e dinâmicas de apoio social ocorridos dentro de redes primárias ou secundárias ${ }^{(5)}$.

A família apresenta-se como a rede social primária que mais apoia seus membros com deficiência visual ${ }^{(15-16,18-23,25)}$ em práticas/ações apoiadoras do tipo: realizar compras, fazer a limpeza da casa, auxiliar com transporte, correio, finanças, levar aos serviços de reabilitação, dar apoio às decisões pessoais, companhia e diá$\log { }^{(15,18-19,21)}$. A família é a primeira instituição de contato das pessoas, por meio dela adquirem-se valores éticos e humanitários, aportes afetivos, desenvolvimento e bem-estar ${ }^{(5,27)}$.

Quando o apoio ofertado pelos membros da rede social é capaz de atender às necessidades globais, mediante o suporte fornecido por diversas redes sociais, incluindo a família, amigos, vizinhos, colegas e outras instituições, nota-se que o nível de estado psicológico da pessoa com deficiência visual modifica-se, a ponto de evitar a ocorrência de sintomas depressivos e aumentar a satisfação com a vida ${ }^{(16)}$.

O apoio de vizinhos e familiares proporciona o incentivo moral, o convívio social e a manutenção da resiliência ${ }^{(7)}$. Além da rede primária constituída da família, parceiros românticos, amigos, colegas da escola, de trabalho e vizinhos, a rede secundária formada por instituições e organizações formais e informais também é necessária no cuidado às pessoas cegas ou com baixa visão ${ }^{(5)}$.

A representação cotidiana das pessoas com deficiência visual foi relatada com ênfase nas necessidades adaptativas que a deficiência visual pode desencadear. Essa condição reflete a atuação do profissional terapeuta em reabilitação e a importância desse serviço para oportunizar uma nova realidade, com plenitude, satisfação, reconstrução de ideais, participação social e retomada de atividades individuais ${ }^{(28)}$.

Embora seja relevante e primordial a readaptação clínica visual, percebe-se que, muitas vezes, esse tipo de deficiência não é abarcado no ponto de vista do holismo e totalizante do ser. Essa abordagem ideológica controversa, de cunho político e cultural, é produto de uma sociedade que frequentemente associa a pessoa com deficiência visual como "portadores" de características profundamente diferenciadas das outras pessoas, gerando preconceito, exclusão e estigma social ${ }^{(29)}$.

O enfermeiro, na prestação de cuidados em saúde às pessoas com deficiência visual, deve realizar visita domiciliar constante, ofertar apoio informativo, emocional, instrumental e presencial. Na perspectiva do processo de educação em saúde, o enfermeiro deve garantir uma assistência integral, inclusive os encaminhamentos a serviços de referência especializados e às Unidades de Apoio à Família ${ }^{(19,25)}$. Essas ações necessitam do conhecimento técnico-científico e habilidades para assistir e comunicar-se com pessoas cegas, garantindo a acessibilidade visual ${ }^{(30)}$.

Tal fato foi percebido entre enfermeiros de uma unidade hospitalar que cuidam de pacientes cegos, na qual a falta de conhecimento e despreparo técnico para lidar com essa clientela demandou a adoção de atitudes simples, como apresentar-se enquanto profissional ao entrar no espaço do paciente, evitar o uso de comunicação não verbal e descrever o ambiente. Portanto, torna-se visível a necessidade de capacitação para aquisição de habilidades comunicativas e de repertório para informações específicas que atendam às necessidades de pacientes com essa deficiência ${ }^{(3)}$.

Entre os tipos de apoio, o instrumental foi predominante, revelando-se como assistência prática que permite ao cego melhor desempenho de suas funções pessoais, ocupacionais e sociais $^{(17,23)}$. O apoio emocional também se mostrou aparente, e pode ser visto como suporte capaz de elevar a autoestima, aprovação de suas atitudes e iniciativas, caracterizando-se como o tipo de apoio essencial em momentos de dificuldades para alcançar o bem-estar ${ }^{(20,24)}$.

O apoio emocional está relacionado à percepção de ser cuidado, apoiado e valorizado por alguém efetivamente disponível, com atitudes de empatia, preocupação, carinho e valorização da pessoa; por outro lado, a assistência prática e direta na realização de atividades concretas/diárias ou resolução de problemas constitui o apoio instrumental $^{(31)}$. O apoio informativo apresenta-se 
como ações voltadas à oferta de conselhos e esclarecimentos de dúvidas acerca da deficiência visual. Percebe-se que, em determinados momentos, ocorre excesso na oferta de informações, mas esse tipo de apoio é salutar, principalmente em estágios iniciais da deficiência ${ }^{(25)}$.

No que se refere ao apoio presencial, este é bastante identificado, uma vez que a pessoa cega ou com baixa visão, na impossibilidade de realizar determinadas tarefas, necessita de outras pessoas videntes, geralmente um familiar, para auxiliá-las ${ }^{(17)}$. O Autoapoio refere-se à autoconfiança e o acreditar em si mesmo; é quando o cego, mesmo diante de todas as circunstâncias, é um exemplo de ajustamento, seguro de si e com boa autoestima ${ }^{(22)}$.

O contexto de vida social e pessoal da deficiência visual perpassa por circunstâncias, como insatisfação com a vida, sensação de mal-estar, morar sozinho e/ou longe da família, depressão e sentimentos de ansiedade $\mathrm{e}^{(15-16,19,23-24)}$. Tais fatores são visíveis em diagnósticos de doenças crônicas que provocam impactos frequentemente estressantes e perceptíveis na deficiência visual ${ }^{(32)}$, o que oportuniza a existência de elevados níveis de sofrimento emocional ${ }^{(33)}$.

A associação entre a depressão e a deficiência visual foi percebida como significativa, pois sua prevalência nessa população adulta é de aproximadamente $14 \%{ }^{(34)}$. Essa condição reflete o aumento da incapacidade funcional e as dificuldades para realizar atividades da vida diária, como ler um livro, conduzir algo e andar sozinho ${ }^{(35)}$. Nesse sentido é que a rede social de apoio às pessoas com deficiência visual precisa ser identificada e acessada.

As práticas apoiadoras, como o auxílio à mobilidade, ensino de técnicas relativas às atividades diárias, suporte no uso de habilidades, disponibilidade para aconselhamentos e encorajamento $^{(15-16,21,23)}$, não são suficientes para atender integralmente as necessidades dos usuários com deficiência visual, uma vez que é essencial a valorização da competência e independência dessas pessoas ${ }^{(18)}$. É necessário apoio social que preze por sua autonomia, de tal maneira que as encoraje à independência pessoal e ao exercício da cidadania ${ }^{(28)}$.
A autonomia da pessoa cega ou com baixa visão revela sua condição de domínio sobre o ambiente físico e social, resguardando sua privacidade e dignidade. Paralelo ao conceito de autonomia, a independência é a faculdade de decisão sem depender de outrem, alcançada pelo empoderamento da pessoa, que usa seu poder para fazer escolhas, tomar decisões e assumir o controle de sua vida ${ }^{(36)}$.

A construção da identidade e autonomia podem ser adquiridas no cenário escolar por intermédio de colegas e apoio dos professores, principalmente na educação especializada, que proporcionem interação e despertem o conhecimento do educando, mediante o uso de recursos pedagógicos de acessibilidade escolar ${ }^{(37)}$. Além desse cenário, o ambiente de trabalho pode favorecer o desenvolvimento de socialização, autoestima e capacidade profissional, revelando a importância da inclusão de pessoas com deficiência, inclusive visual, no mundo do trabalho ${ }^{(38)}$.

Evidencia-se como limitações a ausência de abordagem dos aspectos sociodemográficos nos artigos analisados, assim como de questões culturais e religiosas, o que caracteriza uma lacuna e talvez justifique os apoios da rede social ora evidenciados. Espera-se que esta pesquisa proporcione maior ênfase nas práticas apoiadoras das pessoas com deficiência visual, sobretudo no campo de atuação em saúde e enfermagem.

\section{Conclusão}

As principais práticas apoiadoras ofertadas pela rede social no cotidiano das pessoas com deficiência visual foram disponibilidade para escuta, diálogo, companhia social, ajuda prática na limpeza da casa, realização de compras, auxílio com transporte e assistência doméstica no geral. Ficou evidente que tais práticas melhoram a autoestima, favorecem a autonomia e facilitam as atividades de vida diária.

A família constitui-se como a rede social que mais fornece suporte aos seus entes com deficiência visual, seguida de amigos, colegas, professores e profissionais da saúde. Embora haja a necessidade de que essas pessoas sejam compreendidas e ajudadas integralmente, o apoio 
recebido ocorre principalmente nas questões relacionadas às tarefas diárias e adaptação à nova realidade.

Os estudos enfocam as pessoas com deficiência visual em diversas fases do ciclo vital, o que demanda da rede social a necessidade de articular cuidado e educação, sendo esta essencial para favorecer, nos mais diversos cenários, a inserção social. Nesse sentido, as práticas apoiadoras podem influenciar a construção de uma postura de autoconfiança e autonomia frente aos desafios e às limitações enfrentados cotidianamente pelas pessoas cegas e/ou com baixa visão.

\section{Colaborações:}

1 - concepção, projeto, análise e interpretação dos dados: Jones Sidnei Barbosa de Oliveira;

2 - redação do artigo e revisão crítica relevante do conteúdo intelectual: Jones Sidnei Barbosa de Oliveira e Cleide Maria Pontes;

3 - aprovação final da versão a ser publicada: Luciana Pedrosa Leal e Estela Maria Leite Meirelles Monteiro.

\section{Referências}

1. Word Health Organization. Blindness and vision impairment [Internet]. Geneva $(\mathrm{CH})$; 2021 [cited 2021 Dec 6]. Available from: https:// www.who.int/news-room/fact-sheets/detail/ blindness-and-visual-impairment

2. Instituto Brasileiro de Geografia e Estatística. Pesquisa nacional de saúde 2013: ciclos de vida: Brasil e grandes regiões [Internet]. Rio de Janeiro (RJ); 2015 [cited 2018 Sep 18]. Available from: https://biblioteca.ibge.gov.br/visualizacao/livros/ liv94522.pdf

3. Favretto DO, Carvalho EC, Canini SR. Interventions performed by nurses to improve communication with the visually impaired. Rev Rene [Internet]. 2008 [cited 2018 Sep 18];9(3):6873. Available from: http://periodicos.ufc.br/rene/ article/view/5065/3715

4. Souza EL, Moura GN, Nascimento JC, Lima MA, Pagliuca LM, Caetano JA. Nursing diagnoses based on the self-care theory in people with visual deficiency. Rev Rene [Internet]. 2012 Jun [cited 2018
Aug 10];13(3):542-51. Available from: http://www. periodicos.ufc.br/rene/article/view/3975/3139

5. Sanicola L. As dinâmicas de rede e o trabalho social. São Paulo: Veras; 2015.

6. Holanda CMA, Andrade FLJP, Bezerra MA, Nascimento JPS, Neves RF, Alves SB, et al. Support networks and people with physical disabilities: social inclusion and access to health services. Ciênc saúde coletiva. 2015 Jan;20(1):175-84. DOI: http://dx.doi.org/10.1590/ 1413-81232014201.19012013

7. Cezario KG, Oliveira PMP, Sousa AAS, Carvalho QCM, Pennafort VPS, Santos LAPF. Blind parentes and nutrition of children: experiences and care. Rev Rene. 2016;17(6): 850-7. DOI: https://doi.org/10.15253/2175-6783. 2016000600017

8. Fernandes AC, Montilha RCI. The comprehensive evaluation in speech therapy for people with visual impairments: a case report. Rev CEFAC. 2015;17(4):1362-9. DOI: https://doi. org/10.1590/1982-0216201517420314

9. Soares CB, Hoga LAK, Peduzzi M, Sangaleti C, Yonekura $\mathrm{T}$, Silva DRAD. Integrative Review: Concepts and Methods Used in Nursing. Rev esc enferm USP. 2014;48(2):335-45. DOI: https://doi. org/10.1590/S0080-6234201400002000020

10. Mendes KDS, Silveira RCCP, Galvão CM. Integrative literature review: a research method to incorporate evidence in health care and nursing. Texto contexto - enferm. 2008;17(4): 758-64. DOI: https://doi.org/10.1590/S0104-07072 008000400018

11. Galvão TF, Pansani TA, Harrad D. Principais itens para relatar Revisões sistemáticas e Meta-análises: A recomendação PRISMA. Epidemiol Serv Saúde. 2015;24(2):335-42. DOI: https://doi. org/10.5123/S1679-49742015000200017

12. Stetler CB, Morsi D, Rucki S, Broughton S, Corrigan B, Fitzgerald J, et al. Utilization-focused integrative reviews in a nursing service. Appl Nurs Res. 1998;11(4):195-206. DOI: https://doi. org/10.1016/s0897-1897(98)80329-7

13. Melnyk BM, Fineout-Overholt E, editors. Evidence-based practice in nursing \& healthcare: A guide to best practice. 2nd ed. Philadelphia: Lippincott Williams \& Wilkins; 2011.

14. Ursi ES, Gavão CM. Prevenção de lesões de pele no perioperatório: revisão integrativa da literatura. Rev Latino-Am Enfermagem. 2006;14(1):124-31. 
DOI: https://doi.org/10.1590/S0104-11692006000 100017

15. Cimarolli VR, Boerner K, Reinhardt JP, Horowitz A. Perceived overprotection, instrumental support and rehabilitation use in elders with vision loss: A longitudinal perspective. Psychol Health. 2013;28(4):369-83. DOI: https://doi.org/10.1080/ 08870446.2012 .729835

16. Guerette AR, Smedema SM. The Relationship of Perceived Social Support with Well-Being in Adults with Visual Impairments. J Vis Impair Blind. 2011;105(7):425-39. DOI: https://doi.org/10. 1177/0145482X1110500705

17. Papakonstantinou D, Papadopoulos K. Social Support in the Workplace for Working-Age Adults with Visual Impairments. J Vis Impair Blind. 2009;103(7):393-403. DOI: https://doi. org/10.1177/0145482X0910300703

18. Singletary C, Goodwyn MA, Carter AP. Hope and Social Support in Adults who are Legally Blind at a Training Center. J Vis Impair Blind. 2009;103(8):500-4. DOI: https://doi. org/10.1177/0145482X0910300808

19. Hong T, Mitchell P, Burlutsky G, Fong CSU, Rochtchina E, Wang JJ. Visual Impairment and Subsequent Use of Support Services Among Older People: Longitudinal Findings From the Blue Mountains Eye Study. Am J Ophthalmol. 2013;156(2):393-9. DOI: https://doi.org/10.1016/j. ajo.2013.04.002

20. Kef S, Deković M. The role of parental and peer support in adolescents well-being: a comparison of adolescents with and without a visual impairment. J Adolesc. 2004;27(4):453-66. DOI: https://doi.org/10.1016/j.adolescence.2003.12.005

21. Barbieri MC, Broekman GVDZ, Souza ROD, Lima RAG, Wernet M, Dupas G. Rede de suporte da família da criança e adolescente com deficiência visual: potencialidades e fragilidades. Ciênc saúde colet. 2016;21(10):3213-23. DOI: https://doi.org/10.1590/1413-812320152110. 19562016

22. Pagliuca LMF, Uchoa RS, Machado MMT. Pais cegos: experiências sobre o cuidado dos seus filhos. Rev Latino-Am Enfermagem. 2009;17(2):271-4. DOI: https://doi.org/10.1590/S0104-11692009000 200021

23. Pinquart M, Pfeiffer JP. Perceived social support in adolescents with and without visual impairment. Res Dev Disabil. 2013;34(11):4125-33. DOI: https://doi.org/10.1016/j.ridd.2013.08.004

24. Kempen GIJM, Ballemans J, Ranchor AV, Van Rens GHMB, Zijlstra GAR. The impact of low vision on activities of daily living, symptoms of depression, feelings of anxiety and social support in community-living older adults seeking vision rehabilitation services. Qual Life Res. 2012;21(8):1405-11. DOI: https://doi.org/10.1007/ s11136-011-0061-y

25. Boyce T, Dahlmann-Noor A, Bowman R, Keil S. Support for infants and young people with sight loss: a qualitative study of sight impairment certification and referral to education and social care services. BMJ Open. 2015;5(12):e009622. DOI: http://dx.doi.org/10.1136/bmjopen-2015-009622

26. Instituto Brasileiro de Geografia e Estatística. Censo demográfico 2010. Características gerais da população, religião e pessoas com deficiência [Internet]. Rio de Janeiro (RJ); 2012 [cited 2018 Aug 18]. Available from: https://biblioteca.ibge.gov. br/visualizacao/periodicos/94/cd_2010_religiao_ deficiencia.pdf

27. Magro NA, Trevisol MTC. Escola, família e a construção de valores: um estudo a partir da ótica de pais e profissionais da educação. Leopoldianum [Internet]. 2014 [cited 2018 Aug 10];40(110-2):3749. Available from: http://periodicos.unisantos.br/ leopoldianum/article/view/482

28. Aciem TM, Mazzotta MJS. Personal and social autonomy of visually impaired people who were assisted by rehabilitation services. Rev Bras Oftalmol. 2013;72(4):261-7. DOI: https://doi. org/10.1590/S0034-72802013000400011

29. Nunes S, Lomônaco JFB. The blind student: prejudices and potentialities. Psicol Esc Educ. 2010;14(1):55-64. DOI: https://doi.org/10.1590/ S1413-85572010000100006

30. Gomes TM, Costa KNFM, Costa TF, Martins KP, Dantas TRA. Health service accessibility for the visually impaired. Rev enferm UERJ. 2017;25:e11424. DOI: http://dx.doi.org/10.12957/reuerj.2017.11424

31. Souza MHN, Souza IEO, Tocantins FR. Abordagem da fenomenologia sociológica na Investigação da mulher que amamenta. Rev enferm UERJ. 2009 [cited 2018 May 23];17(1):52-6. Available from: http://files.bvs.br/upload/s/0104-3552/2009/ v17n1/a009.pdf

32. Bambara JK, Wadley V, Owsley C, Martin RC, Porter C, Dreer LE. Family Functioning and Low 
Vision: A Systematic Review. J Vis Impair Blind. 2009;103(3):137-49. DOI: https://doi.org/10. 1177/0145482X0910300303

33. Dibajnia P, Moghadasin M, Madahi ME, Keikhayfarzaneh MM. Depression among low vision patients. Health MED [Internet]. 2013 [cited 2018 Sep 13];7(3):832-6. Available from: https:// scholar.google.com/citations?view_op=view_ citation\&hl=en\&user=h2uI4OMAAAAJ\&citation for_view=h2uI4OMAAAAJ:_FxGoFyzp5QC

34. Evans JR, Fletcher AE, Wormald RP. Depression and Anxiety Invisually Impaired Older People. Ophthalmology. 2007;114(2):283-8. DOI: https:// doi.org/10.1016/j.ophtha.2006.10.006

35. Renaud J, Bédard E. Depression in the elderly with visual impairment and its association with quality of life. Clin Interv Aging. 2013;8:931-43. DOI: https://doi.org/10.2147/CIA.S27717
36. Sassaki RK. Os novos paradigmas. In: Sassaki RK. Inclusão: construindo uma sociedade para todos. $7 \mathrm{a}$ ed. Rio de Janeiro (RJ): WVA; 2006. p. 26-57.

37. Sousa ACLL, Sousa IS. A inclusão de alunos com deficiência visual no âmbito escolar. Estação Científica (UNIFAP). 2016;6(3):41-50. DOI: https:// doi.org/10.18468/estcien.2016v6n3.p41-50

38. Neves-Silva P, Prais FG, Silveira AM. The inclusion of disabled persons in the labor market in Belo Horizonte, Brazil: scenario and perspective. Ciênc saúde coletiva. 2015;20(8):2549-58. DOI: https:// doi.org/10.1590/1413-81232015208.17802014

Recebido: 5 de agosto de 2020

Aprovado: 28 de junho de 2021

Publicado: 26 de janeiro de 2022

A Revista Baiana de Enfermagem utiliza a Licença Creative Commons - Atribuição-NãoComercial 4.0 Internacional.

https://creativecommons.org/licenses/by-nc/4.0/

Este artigo é de acesso aberto distribuído sob os termos da Licença Creative Commons (CC BY-NC).

Esta licença permite que outros remixem, adaptem e criem a partir do seu trabalho para fins não comerciais. Embora os novos trabalhos tenham de lhe atribuir o devido crédito e não possam ser usados para fins comerciais, os usuários não têm de licenciar esses trabalhos derivados sob os mesmos termos. 